\title{
Laws on Drug Trading Conditions are applied in Practice in Dong Nai Province \\ Luong Quynh Trang ${ }^{1 *}$
}

${ }^{1}$ Master's degree, major in Economic Law, Tra Vinh University, Tra Vinh, Viet Nam

DOI: $10.36348 /$ sijlcj.2021.v04i04.007 $\quad$ | Received: 15.03.2021 | Accepted: 21.04.2021 | Published: 27.04 .2021

*Corresponding author: Luong Quynh Trang

\section{Abstract}

The study of the topic aims to clarify some theoretical issues about drugs and drug trading, the contents of current legal regulations on drug trading conditions, and practical application in Dong Nai province. On that basis, we can see the problems and shortcomings of the current law and propose a number of solutions to improve and improve the effectiveness of the application of the law on drug trading conditions in Vietnam in general and Dong Nai province in particular. To achieve that goal, this study focuses on the following contents: Analyzing the practice of drug trading in Dong Nai province, on that basis pointing out the limitations and shortcomings in the implementation of the law on drug trading lawsuits; analyzing the current legal status of drug trading conditions to point out inadequacies in the provisions of the law on the stated issue; provides a number of orientations, specific solutions, and recommendations to improve and improve the effectiveness of the application of the law on drug trading conditions.

Keywords: Laws on drug trading, conditions applied, Dong Nai province, Vietnam.

Copyright (c) 2021 The Author(s): This is an open-access article distributed under the terms of the Creative Commons Attribution 4.0 International License (CC BY-NC 4.0) which permits unrestricted use, distribution, and reproduction in any medium for non-commercial use provided the original author and source are credited.

\section{INTRODUCTION}

Medicines are an important item in the care and protection of people's health, put under a special management form. The drug market also contributes significantly to the socio-economic development of the locality as well as of the country.

Vietnam's pharmaceutical market in 2019 is estimated at $\$ 6.5$ billion, according to Business Monitor International. In which, the non-prescription drug market (OTC) is estimated at 1.6 billion USD, the average growth forecast in the period 2019-2022 is $9.5 \%$ / year, the annual pharmaceutical consumption scale is about $4, \$ 5$ billion, the size of the mobile phone market, and double-digit growth.

According to the latest statistics, per capita, spending on drugs in Vietnam has increased by 37.97 USD in 2015, about 56 USD in 2017, and has maintained spending on pharmaceuticals at a growth rate of at least 14\%./year until 2025. Market research firm IMS Health also forecasts that spending on pharmaceuticals per capita in Vietnam will increase to $\$$ 50/person/year by 2020. The organization of business services. Currently, drug dealers are creating favorable conditions for people to access when needed, the medicine supply system through retail stores such as pharmacies, drugstores are and will be increasingly developed, especially in the large urban areas.

The legal corridor for this business model has basically been quite complete since the 2005 Pharmaceutical Law was born and revised in 2016 [1]. However, in practice, the implementation of pharmacies, retail drugstores in the There are still certain limitations in the locality due to the lack of uniformity in the legal system such as decrees and circulars, and inconsistency with the main legal documents, leading to conflicts in understanding and implementation law, not feasible in implementation [2]. There are also many shortcomings in the management of drug prices and tax administration for retail establishments, which have not created favorable conditions for establishments to develop and compete fairly, in general, drug prices are still high, especially for special medicine.

Dong Nai is the 5th most populous province in the country with more than 3 million people, an area of nearly $6000 \mathrm{~km}$, the need for medical examination and treatment is huge, but the health system cannot meet the needs of the people, so Retail establishments are thriving, especially in densely populated urban areas. In 
Luong Quynh Trang., Sch Int J Law Crime Justice, Apr, 2021; 4(4): 233-240

the whole province, there are 2881 pharmacies and drugstores operating on a variety of scales, from small establishments to large companies and drugstores dominating the market.

Although the system of drug dealers for people is relatively developed, there are still many problems arising from practice management, drug trading conditions, selling overdue drugs, selling unlisted drugs price listing, selling drugs without a prescription, etc. damaging the interests of the people and the state, leading to a series of problems that need to be solved in law [3]. From the above analysis, it is necessary to have legal studies related to drug trading in order to have legal proposals for the stable development of the system of drug supply establishments, meeting the requirements serving the people and contributing to economic development. On that basis, the author selected the topic: "Lawson drug trading conditions through practice in Dong Nai province" as the research topic.

\section{LITERATURE REVIEW}

Vietnam is a country with a large population, according to the latest 2019 survey of over 90 million people, ranking 13th in the world, however, the aging rate is happening rapidly, so the demand in terms of medical examination and treatment and the use of medical services is increasingly high. According to the Vietnam Social Insurance report in 2019, the number of people going for medical examination and treatment with health insurance has reached 186 million times. The health insurance fund's expenditure on medical examination and treatment is also increasing, from 15.5 trillion VND (970 million USD) in 2009, to over 100 trillion VND (equivalent to about 4 billion USD). In 2019 , if you include about $20 \%$ of patients who do not have health insurance, the actual costs for medical examination and treatment will increase a lot. It is estimated that in the cost of medical examination and treatment, the cost for medicine is about $30-40 \%$, so the drug market continues to grow, for many consecutive years the pharmaceutical industry in Vietnam has always grown at 2 digits. According to BMI Research, in 2018, the scale of the Vietnamese pharmaceutical industry was worth 5.9 billion USD, up $11.5 \%$ over the previous year, which helped Vietnam become a large pharmaceutical market second in Southeast Asia is one of the 17 countries ranked in the group with the highest pharmaceutical industry growth.

BMI Research assessed that, despite having many difficulties in production and technology, with a young population structure, it is rapidly aging, income, environmental pollution, and interest level of over 97 million. Increasing people to health problems will be the driving force for the pharmaceutical industry to continue to grow.

In the next 5 years, Vietnam's pharmaceutical industry is expected to continue to be in the group of 20 countries with the strongest and most stable growth in the world.

Forecasts from IBM market research firm on the size of our country's pharmaceutical market will reach $\$ 7.7$ billion by 2021 , and up to $\$ 16.1$ billion by 2026 , with a compound growth rate of $11 \%$ calculated in Vietnam dong.

According to the survey results of the Vietnam Report, $100 \%$ of experts also said that Vietnam's pharmaceutical industry in the period of 2019-2020 will continue to grow at a double-digit rate, of which nearly $80 \%$ of experts believe that growth will be continued to stabilize at $10-15 \%$.

With a large population, rapid aging rate, degraded environment, sedentary lifestyle has and will increase the need for drug use of people, the system of pharmacies, drugstores have been born and increasingly developed. In recent years, per capita, spending on pharmaceuticals in Vietnam has increased rapidly. Particularly in 2017, the average spending on drugs of Vietnamese people was about 56 USD / person (about 1.3 million VND) and increased to 124 USD (equivalent to nearly 2.9 million VND) in 2018 (according to the Medical Organization) world economy in the Western Pacific region and the OECD organization). Taking into account health expenses, the proportion of drug spending in Vietnam is $33 \%$, at a rather high level, $44 \%$ in Cambodia, 39\% in China, $34 \%$ in Thailand, and $16 \%$ in Australia.

The establishment of a medicine and pharmaceutical trading system has met the needs of medicines for treating diseases for people and supplementing the medicine supply system of medical establishments. With easy access, flexible time, and diversified drug products, the drug retail business system is increasingly trusted and supported by the people.

Subject: "Survey on the performance of Phuc An pharmacy, District 9, Ho Chi Minh City in 2015", Thesis of Specialized Pharmacist I of Hanoi University of Pharmacy in 2016 by Tran Thi Hoai Dat [4] analyzed a The number of factors related to pharmacist qualifications for drug trading, to some of the benefits of applying good pharmacy practice standards and implementing GPP requirements. The author also gives comments on the activities of the World Health Organization.

In the article "State management of drug business in Hanoi" by Truong Dinh Tien, published in the State Management Journal, No. 8, 2017, pages 3437 , the author generalized State management system for business activities in Vietnam in general and in Hanoi in particular, highlighting the weaknesses in State management which are mainly caused by the 
inadequacies in the law business management and the lack of expertise and profession of State management officials. On that basis, the author proposes remedial solutions.

The management of drug prices in the implementation is also confusing, although drugs are essential commodities that require special control and subsidized when there is an economic downturn like during the Covid 19 epidemic which is occurring. According to TTV (Thanh Hoa radio and television station), within the past 5 months, consumers have witnessed the dizzying price increases of many western medicines such as Efferalgan 150 with retail prices from 11,000 - 12,000 VND/package (up 7 times); Efferalgan 250 from 19,500 to $21,000 \mathrm{VND} /$ pack (up nearly 8 times); The retail price of Berlthyrox 100 drug ranges from 28 to $35,000 \mathrm{VND} /$ pack (increasing by more than 2 times). Some special drugs also increased strongly such as Pregnyl, IVF.C, etc.

It is worth mentioning that up to now, the declared and re-declared wholesale prices announced on the website of the Ministry of Health have not increased. Accordingly, Efferalgan 250 has a declared price of 3,515 VND/package; Berlthyrox 100 is priced at $490 \mathrm{VND} /$ tablet (equivalent to 12,500 VND / blister). Similarly, the brand-name drugs Pregnyl and IVF.C also have a much lower wholesale price than the market price. There were clearly signs of speculation and unreasonable drug-hoarding. In addition, the difference in retail drug prices on the market makes consumers wonder.

According to Decree 54/ND-CP, dated May 8, 2017 [5], of the Government, detailing the implementation of the Law on Pharmacy: pharmacy business establishments are responsible for fully implementing the regulations on price listing and declaration and re-declaring drug prices; not to sell drugs without the declared or re-declared prices announced on the website of the Ministry of Health; must not sell drugs at prices higher than announced or re-declared prices.

For retail drug prices, the Decree only stipulates that profits for drugs sold at drug retailers within the medical examination and treatment establishments must not exceed $15 \%$ of the wholesale prices. However, the monopoly situation of many drugs in some hospitals also causes frustration for people. The country currently circulates more than 20,000 modern medicines. If the management is not strictly implemented, retail drug price disorder is inevitable and the sufferer is still the patient.

Subject: "The law on medicine business in Vietnam", Master of jurisprudence thesis of author Tran Thi Minh Tam at Law Faculty of Hanoi National University in 2015 [6], thesis of author Tam It has an approach similar to the author's research direction but applies the 2005 pharmaceutical law and focuses on a wide area analysis covering many issues from the production, circulation of goods, import and export. Many issues applying the 2005 law have changed and updated, requiring further research.

The 2016 Law on Pharmacy [1] also stipulates that drug trading establishments will have to become providers of health insurance drugs, creating conditions for patients participating in health insurance to easily receive drugs after medical examination and treatment or visit by family doctors examination and prescribing medicine, reducing the load for hospitals. However, until now, after 3 years of implementing the Pharmaceutical Law 2016, we have not done this yet, leading to the people's rights not being guaranteed in the best way [7].

The same situation occurs in Dong Nai province with nearly 3,000 drugstores and pharmacies supplying the needs of more than 3 million people. Outstanding among the violations committed by private medical and pharmaceutical practice establishments in the province recently is the operation of illegal drug trading establishments, practicing beyond professional capacity, discovering many medical establishments private sector violation [8].

In the first 6 months of 2017, 19/55 private medical facilities were inspected for violations by the Inspector of the Department of Health with a total administrative fine of over 400 million VND. The main contents of violation are: practicing without a certificate, having an operation license, having a certificate of eligibility for drug trading, both providing medical examination and dispensing drugs, practicing beyond the professional capacity selling expired drug items. Taking advantage of the epidemic situation, many drug stores have committed acts of hoarding products, raising the selling prices of masks and supporting drugs for Covid 19 such as reducing Paracetamol fever, Vitamine in effervescent form, making public dissatisfaction.

Therefore, the management of the retail drug trading system based on the law is very important, how to ensure professional factors, ensure health care for the people, and ensure distribution economic development.

\section{RESEARCH RESULTS AND DISCUSSIONS Overview of drug trading conditions}

\section{The concept of drug business conditions}

Business conditions are conditions that are required by law for business entities to have in doing business in certain industries. Business conditions are presented in two forms; 1) Business license (can bear many different names such as certificate of business 
eligibility, license to operate) issued by a competent state agency.

For example, if you want to trade in liquefied gas, to trade in cigarettes, to trade in gasoline, etc., a business entity is only allowed to do business in these lines when licensed by the Department of Trade of the province or centrally run city business; or if wishing to do business in a credit institution (establishing a credit institution), it must obtain a license from the State Bank of Vietnam. The business license is only for a certain period; 2) Regulations on standards of environmental sanitation, food safety, and hygiene, regulations on fire prevention and fighting, social order, traffic safety, and other requirements for doing business (hereinafter referred to as business conditions without a license) [1].

On that basis, it can be understood that drug trading conditions are requirements and standards set by law for an individual or organization to be allowed to trade in drugs. If the business registrant can meet those conditions, he or she will be licensed to trade in drugs.

\section{Classification of drug trading conditions}

Personnel group: Professional person, direct retailer, etc. Pharmaceutical personnel is an indispensable factor in every pharmacy, depending on the scale of operation of the pharmacy, the number of employees is arranged fit. To be able to participate in the drug business, an establishment must meet the requirements of professional responsibility, retailers, etc. whereby these individuals must have papers and qualifications in accordance with the regulations legal. The staffing requirement is the first of all drug trading standards.

Group of material and technical facilities: location, construction conditions, area, drug storage equipment, environment, etc. This group includes the conditions of facilities, equipment serving business joint and drug storage in general. Accordingly, a drug trading establishment needs to have the location, construction works, minimum area, essential equipment for trading, measuring and ensuring drug quality, etc.

Management group: bookkeeping, information technology application, etc. This is a group that includes conditions related to management activities for a drug trading establishment. Accordingly, business establishments must have specific books, papers, and documents as prescribed by law, and at the same time have to own information technology applications with specific functions related to management. Over-thecounter medicine, etc.

Group of activities of pharmacies: buying, selling, preserving, destroying drugs, etc. This group includes conditions on business activities of pharmacies, in which mainly buying and selling activities, storage, and destruction of drugs. In order for a pharmacy to be licensed for business, it is necessary to meet the business process conditions of a drug dealer, such as the conditions for importing and purchasing medicinal ingredients; import of drugs and medicinal ingredients for research and testing purposes; wholesale of drugs and medicinal ingredients; export of drugs and medicinal materials.

\section{Meaning of drug trading conditions}

First, drug business conditions are one of the powerful tools for the State to manage and regulate the market. Medicine is an important field, playing a decisive role in human health. Besides, drug trading is also a lucrative field, thus attracting a lot of individuals and organizations in society to participate in this market. In fact, if the conditions for drug trading are not tied, there will be widespread drug trading, and people with insufficient knowledge and experience will also participate in the drug business. The drugs that are not of sufficient quality will also be put into circulation, which will lead to serious dangers to the health of the people, thereby losing social stability. In addition, if the business conditions for drugs are not bound, the State cannot control the subjects participating in the drug market, thereby losing regulation of the market, leading to the situation of drugs. Counterfeit drugs, smuggled drugs, poor quality drugs will have opportunities to flood the market.

\section{Second, business conditions for drug trading contribute to deciding the structure of the business line}

The regulation of drug trading conditions will help the State to select entities with sufficient financial conditions, knowledge, and experience in participating in the drug trading market. This will help to limit the number of drug dealers in a rampant manner, improve the quality of the drug market, and at the same time ensure a balance between the drug business and other industries in the market school. In other words, the regulation of drug trading conditions will create a barrier to enter the industry, thereby reducing the number of individuals and organizations participating in this industry, while increasing the number of business entities business in other fields, but those fields are switched by subjects from the drug industry. Not only the drug business but many other areas in society have a constraint on business conditions, creating a balance factor like the profession. At the same time, it also creates specialization in the business field of the subjects, because normal business conditions will be bound to matters such as knowledge, experience, facilities [7]. These are the decisive factors that create efficiency in a trader's business, in addition to ensuring the benefits that customers can expect.

Third, drug trading conditions are the basis for competent state agencies to perform the functions of business management as well as dispute resolution, creating stability and development for the economy. 
Luong Quynh Trang., Sch Int J Law Crime Justice, Apr, 2021; 4(4): 233-240

\section{The law concept of drug trading conditions}

Any field, any social relationship that arises in social life also needs the adjustment of the law to orient these relationships in a unified general order the interests of the State, the parties to the relationship, and the common interests of the whole society. The law is considered one of the most effective ways to perform state management functions. The legal system is divided into different constituent parts to regulate groups of separate social relations, but have an interaction with each other, ensure that these relationships exist, develop conformity to the law.

The social relationships arising in the drug business are diversified and complicated, including social relationships arising between business entities and competent State management agencies, together with relationships between drug dealers and other individuals and organizations that are drug users.

The social relations in the pharmaceutical sector in general and drug trading conditions in particular, with one side being the entity with State power are usually administrative-state relations, in this field, the Weakness is related to the business registration order and procedures and the fulfillment of drug trading conditions. In general, these relationships are established and implemented in a fairly simple and clear way., dispute. In addition, the law also provides very specific and clear provisions for matters related to state management such as competence, order, and procedures for enterprise registration or settlement of complaints and denunciations, etc [7].

For social relationships that arise between drug dealers and other "private" individuals and organizations, these are relationships that often occur with conflicts, disputes, and influences to the interests of traders. This is also one of the key social relations groups that the law on drug trading conditions focuses on.

Violations of the law, harming social relationships regulated by the law on drug trading conditions will be handled by different measures and forms depending on the nature and extent of each Because. State management activities and dispute resolution between traders and customers are governed by many different laws related to the law of many industries such as corporate law, intellectual property law intellectual law, commercial law, civil law, administrative law, criminal law, etc. It can be said that the law on drug trading conditions includes all relevant legal regulations of the industries. Various laws govern the establishment, implementation, and handling of violations in the domain of drug trading conditions.

\section{The situation of drug trading in Dong Nai province} In 2020, Dong Nai is the fifth largest administrative unit in Vietnam in terms of population, third in Gross Domestic Product (GRDP), sixth in GRDP per capita, and 19th in terms of growth rate. Head of GRDP. With 3,097,107 people, GRDP is nearly 400,000 billion VND (equivalent to 17.2 billion USD), GRDP per capita is 124 million VND (equivalent to 5,300 USD), and GRDP growth rate is expected to reach over 9.0 . \%.

Dong Nai is a gateway province to the Southeast economic region - the most developed and dynamic economic region in the country. In which, Dong Nai is one of three sharp corners of the development triangle of Ho Chi Minh City - Binh Duong - Dong Nai. Dong Nai has many traditional industrial clusters and more than 32 industrial zones that have been approved and put into operation by the Prime Minister such as Long Thanh, An Phuoc, Nhon Trach II, Bien Hoa II, Amata, etc.

As of 2019, Dong Nai province's population is $3,097,107$ people, population density is 516.3 people / $\mathrm{km}^{2}$, urban population accounts for $48.4 \%$, rural population accounts for $51.6 \%$. This is also the most populous province in the Southeast with more than 3 million people (excluding Ho Chi Minh City). This is the second-most populous province in the South (after Ho Chi Minh City), the 5th largest in the country (after Ho Chi Minh City, Hanoi, Thanh Hoa, Nghe An), and has the highest urban population. 4th in the country (after Ho Chi Minh City, Hanoi, and Binh Duong).

The province has the second largest area in the Southeast (after Binh Phuoc) and the third in the South (after Binh Phuoc and Kien Giang). According to the General Statistics Office of Vietnam, as of April 1, 2009, Dong Nai province has 51 ethnic groups with foreigners. Of which the Kinh have 2,311,315 people, the Chinese have 95,162 people, the Nung people have 19,076 people, the Tay people have 15,906 people, the Khmer have 7,059 people, and the rest are other ethnic groups such as Muong, Dao, Cham, and Thai. At least the Si La and O Du people have only one person, etc. The urbanization rate by 2020 is over $37 \%$.

\section{Practical application of the law on drug trading conditions in Dong Nai province}

In general, according to the results of inspection and examination and through the author's research, the implementation of conditions for drug trading in Dong Nai province basically meets the regulations. The rate of establishments violating drug trading conditions is very low. Here are some statistics on the current situation of law application in Dong Nai.

About legal documents: On the basis of the test sample of 236 drugstores, the author below statistics the rate of establishments meeting the requirements of legal documents as follows: 
Luong Quynh Trang., Sch Int J Law Crime Justice, Apr, 2021; 4(4): 233-240

Table-1: Conditions Legal documents of drug dealers in Dong Nai [9]

\begin{tabular}{|l|l|l|l|}
\hline Numerical order & Legal record of pharmacy & Number of qualified establishments & Standardized rate \\
\hline 1 & Certificate of practice of pharmacist & 236 & $100 \%$ \\
\hline 2 & Certificate of business registration & 236 & $100 \%$ \\
\hline 3 & Certificate of GPP & 236 & $100 \%$ \\
\hline 4 & Certificate of business eligibility & 236 & $100 \%$ \\
\hline
\end{tabular}

Through the examination results table of legal documents above, it shows that $100 \%$ of the appraised drugstores have complete legal documents as required.

Personnel: Pharmaceutical personnel are an indispensable factor in every pharmacy, depending on the scale of operation of the pharmacy, the number of personnel is appropriately arranged. Surveying the ability to meet personnel standards obtained the following results:

Table-2: Human resource conditions [9]

\begin{tabular}{|l|l|l|l|}
\hline $\begin{array}{l}\text { Numerical } \\
\text { order }\end{array}$ & Standards of personnel & $\begin{array}{l}\text { Number of qualified } \\
\text { establishments }\end{array}$ & $\begin{array}{l}\text { Standardized } \\
\text { rate }\end{array}$ \\
\hline 1 & Employees have the appropriate qualifications & 236 & $100 \%$ \\
\hline 2 & $\begin{array}{l}\text { Employees understand and strictly follow the GPP } \\
\text { principles }\end{array}$ & 230 & $97,5 \%$ \\
\hline 3 & $\begin{array}{l}\text { Having trained staff with professional knowledge, current } \\
\text { pharmacy regulations, and medical laws }\end{array}$ & 228 & $96,4 \%$ \\
\hline 4 & Have health certificates, curriculum vitae as prescribed & 225 & $95,4 \%$ \\
\hline
\end{tabular}

The above survey results show that $100 \%$ of pharmacists are present when evaluating the pharmacy and the staff has the appropriate professional qualifications. However, there are still contents of the drugstores not performing as well as $95.4 \%$ of employees with a health certificate as prescribed, $96.4 \%$ of employees updating current pharmacy knowledge.

About facilities: After the personnel condition is the facilities that the drugstores have to prepare fully, it is a static element, so it is imperative to prepare as required to be considered for a GPP certificate.

Table-3: Conditions in terms of facilities [9]

\begin{tabular}{|l|l|l|l|}
\hline $\begin{array}{l}\text { Numerical } \\
\text { order }\end{array}$ & Standards on facilities & $\begin{array}{l}\text { Number of } \\
\text { qualified } \\
\text { establishments }\end{array}$ & Standardized rate \\
\hline 1 & A drug retailer has a completely separate environment & 236 & $100 \%$ \\
\hline 2 & Dust-proof walls, ceilings, and floors are flat, easy to clean & 236 & $100 \%$ \\
\hline 3 & $\begin{array}{l}\text { There is an arrangement of areas so that non-medicinal } \\
\text { products do not interfere with the drug }\end{array}$ & 236 & $100 \%$ \\
\hline 4 & The exhibition area is preserved from 10m2 - 20m2 & 231 & $97,9 \%$ \\
\hline 5 & $\begin{array}{l}\text { There is a separate dispensing area for drugs, ensuring } \\
\text { hygiene }\end{array}$ & 227 & $96,2 \%$ \\
\hline 6 & There is a consultation area arrangement & 202 & $85,7 \%$ \\
\hline 7 & $\begin{array}{l}\text { The area of the display area to be preserved from 20m2 (plus } \\
\text { points) }\end{array}$ & 34 & $14,4 \%$ \\
\hline
\end{tabular}

Through the survey results, $100 \%$ of drugstores have a satisfactory area, completely separate environment, dustproof walls, walls, and floors that are easy to clean, and have an area arranged so that products are not private medicine does not affect drugs, with $97.9 \%$ of drugstores preserved from $10 \mathrm{~m} 2$ to $20 \mathrm{~m} 2,96.2 \%$ of drugstores have separate areas for drug distribution, hygiene, $95.4 \%$ of drugstores have a handwashing area for drugstores staff and $85.7 \%$ of drugstores have a consultation area, and $14.4 \%$ of drugstores have a storage area of $20 \mathrm{~m} 2$.
Propose perfecting the law on drug trading activities

Firstly, perfecting the law on drug trading conditions applicable to establishments manufacturing drugs and medicinal ingredients. According to Point a, Clause 1, Article 33 of the Law on Pharmacy 2016, an establishment wishing to manufacture drugs and medicinal ingredients must meet a number of statutory criteria, including standards for good practice. However, there are too many regulations on Good Practice, including those that are necessary for people starting a business to manufacture drugs and medicinal ingredients, but there are also standards that only work 
Luong Quynh Trang., Sch Int J Law Crime Justice, Apr, 2021; 4(4): 233-240

for you to people who have been and are doing the process of manufacturing and trading drugs. Thus, it is unreasonable to bring all the provisions of Good Practice to become one of the standards of the manufacture of drugs and medicinal ingredients. The author recommends that it is necessary to separate out specifically which standards of Good Practices will need to meet at the business registration stage, which standards will need to be implemented at the business stage, thereby creating favorable conditions events for other individuals and organizations involved in drug production and trading, and at the same time, it will be consistent with the current practice of social relations in the field of drugs.

Secondly, the conditions on drug wholesale establishments. Under the provisions of Point c, Clause 1, Article 33 of the Law on Pharmacy 2016, an establishment wholesaling drugs and medicinal ingredients must have a place, storage for drugs, storage equipment, means of transport, and a substance management system quantity, technical and human resources to meet Good Distribution Practice, medicinal ingredients. However, the requirement to satisfy the means of transport is unreasonable. In fact, there are many drug wholesalers who sign contracts to transport with a third party that is fully equipped with high-class equipment and means of transportation, or in many cases in the drug wholesale contract, the obligation to transport This is done by the partner, so it is not necessary to ask the wholesaler to respond to the means of transport. This increases barriers to entering the industry of individuals and organizations in need, while this condition is not directly related to the quality of drugs that such establishment's trade. The author recommends that the requirement of means of transport for the business conditions of a drug wholesaler be removed, which may change in the direction of requiring drug wholesalers to satisfy drug storage. The right quality while in transit will ensure the original intention of the legislator but will reduce the barriers to entry for other individuals and organizations.

Thirdly, for the request for drug retail establishments. Requiring drug retailers to have all technical documents is a general requirement. Because of the technical literature on drug retail, there are many different ones, suitable for each stage and different functions and tasks. Therefore, prescribing a general condition as a technical document for the time of registration of a drug retail business is inconsistent with practice. According to the author, lawmakers need to amend or issue detailed instructions for this condition, according to which it is necessary to fully list what types of documents serve what job or function that the establishment sells. Retail medicine is required at the time of business registration. Thus, other documents that are also within the scope of Drug Retailing but do not have any requirements may be updated after the time of business registration, serving the work in the stage of business implementation business or customer care or other requirements to ensure drug quality.

Fourthly, for establishments cultivating and collecting medicinal herbs. The regulation that the establishment cultivates and collects medicinal herbs as a business establishment that does not need a certificate of eligibility for pharmacy business is an inappropriate regulation. In fact, there are many types of medicinal herbs that are complex or pose a threat to social security, although they can serve some purposes of making medicinal herbs for humans, if used on bad motives, these drugs can become preparations or drugs that endanger human health. Therefore, the sourcing control of these medicinal herbs needs to be considered. From the author's point of view, legislators need to issue specific lists of medicinal plants that are allowed to be grown and harvested without the consent or licensing of the competent authority, on that basis. Individuals and organizations cultivating and picking can know which medicines they are allowed to grow and which are not. At the same time, avoid cases where subjects have bad motives, take advantage of this general regulation to produce and supply medicinal herbs on the rare list of medicinal herbs negative effects on human health and social security.

Fifthly, synchronously building, reviewing, and perfecting mechanisms and policies for State management of pharmaceuticals In order to perfect the mechanisms and policies of the State on pharmaceuticals, the State first needs to study checking and forecasting the current state of pharmaceutical production and trading in the domestic market as well as the state's management. At the same time, the State also needs to review unreasonable policies to promptly supplement or amend such as policies related to production, trading, and import of pharmaceuticals to ensure consistency and supply. Reasonable drugs for the domestic market. Medicine is a special commodity with a shelf life and directly related to human health, and it is also an essential commodity for all people. Therefore, in order to improve management efficiency, the State needs to develop synchronous policies to support investment, policies to attract foreign investment, policies to protect domestic production, policies for healthy competition, consumer policy, import policy, integration policy in the pharmaceutical sector, etc.

Sixthly, the State regulates the pharmaceutical market with macro policies and macro tools. The macro policy to regulate the pharmaceutical market is the State's use of indirect methods that do not interfere with the individual activities of enterprises, but through the market to influence enterprises. In addition to the tax policy, the credit policy is a tool to regulate the imported pharmaceutical market, the State also uses the price subsidy policy, the preferential policy for investment in domestic production to make the plan of 
the business. Enterprises are in line with the development plan of the pharmaceutical industry at the same time attracting capital, technological, technical capabilities, and management qualifications from abroad and within the country to improve the efficiency of drug production and business. In order for the State's regulation to take effect, the legal system must combine factors such as synchronous coordination between state management agencies including the Ministry of Planning and Investment and the Ministry of Finance, etc.

Seventhly, to complete the work of pharmaceutical industry development planning and plans. The pharmaceutical industry development plan must achieve the goal of non-pervasive and key pharmaceutical development investment, mobilizing capital sources, maximizing the capacity of machinery and technological level. At the same time, to ensure the requirements of regional and international integration, in particular, to improve the competitiveness of domestically produced drugs with imported drugs and proceed to export. The plan gives directions for businesses to choose where to manufacture, trade, scale, and type of drugs to invest in. The pharmaceutical industry development and planning is oriented and must be based on a scientific basis and feasible in practice. First of all, the Drug Administration of Vietnam needs to research, survey, and investigate the current situation of the medicine production and distribution system as well as the state management in this field to collect statistics on the establishment of the pharmacy profession, the structure and type of enterprise by function; Firm size, capital, machinery, equipment, and technology level.

\section{CONCLUSION}

Regulations of law on drug trading conditions play an important role in the development of the pharmaceutical business. Law is pictured as a "valve regulating the flow of development or inhibiting the development of legal relations".

So how the business of traditional medicines will continue to develop depends on the improvement of the legal system on drug trading conditions in particular and the Law on Pharmacy in general in the coming time. On that basis, the author has studied indepth, explored the conceptual nature and legal status of drug trading conditions, pointed out the practical application of the law, on that basis, proposed immediate solutions as long-term to perfect the legal system on drug trading conditions.

Completion of the pharmacy law in general as well as the law on drug trading conditions, in particular, is a necessary requirement and requires a long process, ranging from small problems to complex problems. Therefore, the Party and Government have paid attention and directed to promptly adjust the business of western medicines.

\section{REFERENCE}

1. Congress. (2016). Pharmaceutical Law, No. 105/2016/QH 13 dated April 6, 2016.

2. Ministry of Health. (2018). Decree 155/2018/ND-CP amending and supplementing a number of provisions related to investment and business conditions under the state management scope of the.

3. Chu, D. H. (2012). Commercial law on drug advertising, Graduation thesis, Hanoi Law University, Hanoi.

4. Tran, Thi Hoai Dat. (2015). "Survey on the results of Phuc An pharmacy in Ho Chi Minh City district 9, 2015". Thesis of Specialist Pharmacist I, Hanoi University of Pharmacy.

5. Government. (2017). Decree No. 54/2017/NDCP dated May 8, 2017, detailing a number of articles and measures to implement the pharmacy law.

6. Tran Thi Minh Tam. (2015). The law on western medicine business in Vietnam. Master's thesis in jurisprudence, Faculty of Law. Hanoi National University.

7. Ministry of Health. (2018). Circular 03/2017/TTBYT, dated February 9, 2018.

8. Dong Nai Department of Health. (2018). Plan 3773/KH - SYT dated August 30, 2018, of the director of implementing the project to strengthen control of drug prescriptions and sale of prescription drugs in Dong Nai province for the period 2018-2020.

9. Dong Nai Department of Health. (2019). Report the results of an inspection and examination of drug trading establishments in Dong Nai Department of Health of Dong Nai province. 